\title{
EDITORIAL
}

\section{Consensus statement on inert gas washout measurement: at the threshold of clinical use}

\author{
Sven M. Schulzke and Urs Frey
}

I nert gas washout tests including single breath washout (SBW) and multiple breath washout (MBW) have been used for several decades across a wide age range spanning from early infancy to late adulthood. In the past, these lung function tests were typically applied in research settings, assessing lung volume and ventilation distribution in order to gain insight into presence, severity and progression of a multitude of diseases, such as chronic lung disease of infancy [1-4], cystic fibrosis [5-9], asthma [10-12] and chronic obstructive pulmonary disease [13-15]. Importantly, inert gas washout detects poor ventilation distribution in the presence of normal spirometry [16]. Until recently, inert gas washout testing was characterised by highly specific and at times incompletely validated hardware environments, customised software for data acquisition and analysis, and a general lack of consensus on criteria for processing and quality control of washouts across age groups. Thus, comparison and generalisability of study results from different laboratories testing patients with different diseases at different ages was extremely difficult. In this issue of the European Respiratory Journal, an international expert group of the European Respiratory Society (ERS) and American Thoracic Society (ATS) takes an important step forward towards overcoming some of the most demanding issues, by publishing a comprehensive statement on inert gas washout measurements [17].

The consensus statement represents an enormous collaborative effort. It is relevant to manufacturers, researchers, clinicians and respiratory technicians, and is intended for the testing of infants, children and adults. Consequently, application of specific tests to different age groups may require age-specific assumptions, extrapolations and modifications of technique. In this very detailed paper and online supplement, the authors describe general equipment requirements, adequate quality control and validation processes of washout systems. They further explain available washout outcomes and factors influencing their calculation, as well as background information on physiological concepts and underlying mechanisms of ventilation distribution. Finally, they provide recommendations on criteria for the acceptability of tests and areas of urgent future research.

University Children's Hospital and University of Basel, Basel, Switzerland.

CORRESPONDENCE: S.M. Schulzke, University Children's Hospital Basel, Spitalstrasse 33, CH4056 Basel, Switzerland. E-mail: sven.schulzke@unibas.ch
On the basis of a large body of research resulting from a multitude of methodological, physiological and epidemiological studies, SBW and MBW tests are now making an appearance in the clinical field. First trials have already used these methods to measure clinically relevant changes in respiratory outcomes and the effects of interventions in clinical trials. For example, lung clearance index (LCI) reflects treatment effects of hypertonic saline and dornase alfa in paediatric patients with cystic fibrosis [18, 19]; normalised phase III slope analysis predicts asthma control in adults following inhaled corticosteroid dose titration [20] and detects improvement in small airway function after smoking cessation in smokers with normal spirometry [21]. The question of whether to focus on indices of ventilation distribution derived from SBW versus those obtained by MBW depends on the intended use; SBW tests are shorter but they require specific breathing manoeuvres which cannot be reliably performed by patients with very severe respiratory disease or by very young children. However, MBW tests necessitate considerably more time but assess ventilation distribution at resting lung volume and can be performed during normal tidal breathing.

Not only for interventional studies, but also for the purpose of monitoring disease progression, both SBW and MBW methods are on the verge of clinical application. For example, several centres already measure LCI on routine follow-up of infants and preschool children who were diagnosed with cystic fibrosis following newborn screening, given that this index may allow for early detection of air trapping [22] and may potentially influence therapy. New applications of SBW and double tracer gas show that SBW phase III slope is an early marker of cystic fibrosis lung disease that can be obtained rapidly in school-aged children with cystic fibrosis [9] using commercially available equipment.

An important step for the implementation of the technique on a large scale, however, is the confidence of the users in the quality of the commercially available equipment, in the adherence of the equipment to the standards and the availability of validated normative values. Since both standards and sophisticated lung models incorporating BTPS (body temperature, ambient pressure, saturated with water vapour) conditions [23] to test devices are now available, it is therefore of utmost importance that manufacturers use the current guidelines and implement hardware and software such that equipment meets the proposed standards, including upto-date normal values and inert gas specific reference equations [24]. Clearly, only standardised testing will allow 
for valid and comparable measurements in various settings and adherence to those standards will prove critical for the introduction of inert gas washout into clinical practice. Arguably, adherence to ERS/ATS standards and implementation of appropriate age-specific reference equations should be mandatory for manufacturers and will be a key selling factor when approaching clinicians interested in complementing their clinical lung function laboratories with washout systems.

What are the targets of future technical development in this field? In clinical practice, the consultation time available, the robustness of a technique and the simplicity and user friendliness are the key issues for success. In recent developments, it has been proposed that SBW could provide similar physiological information as the MBW with the advantage that the procedure is much shorter and easier to perform [9]. Recent work even challenged whether or not MBW per se could potentially be shortened and optimised by re-evaluating cutoffs for final tracer gas concentration, permitting reliable assessment of lung volume and ventilation distribution without unnecessarily prolonging test duration $[9,25,26]$.

Furthermore, to facilitate clinical use, criteria for acceptability of outcomes should be defined for different ages of patients and be weighed against feasibility in a clinical environment, with the ultimate goal of having a test that is both sufficiently accurate and feasibly performed within the known limitations of a busy respiratory clinic [27, 28].

In a routine clinical environment, inert gases are often not available, whereas oxygen is cheap and available in nearly every room of the hospital. Thus, primarily using oxygen as a test gas, and washing out nitrogen from the lung may help to keep costs under control and to streamline transition into clinical practice. Apart from neonates and very young infants who may be subject to changes in breathing pattern, or even develop retinopathy when exposed to high concentrations of inspired oxygen $[29,30]$, nitrogen washout may eventually become the preferred setup from preschool age right through to late adulthood.

Which lung function test is now best? The consensus statement is a huge step towards bringing a very promising and noninvasive technique closer to clinical application. Future studies need to show whether clinical decision-making will be improved using inert gas washout in children with chronic lung disease. However, we may also have to distance ourselves from the idea that each and every lung disease can be monitored with just one type of lung function test. The MBW technique may be useful in specific diseases such as cystic fibrosis but may not be as helpful in others such as chronic lung disease of infancy. In the context of personalised medicine, we should adapt our diagnostic instruments to the age of patients, type of disease and clinical question at hand.

\section{STATEMENT OF INTEREST}

None declared.

\section{REFERENCES}

1 Hjalmarson O, Sandberg KL. Lung function at term reflects severity of bronchopulmonary dysplasia. J Pediatr 2005; 146: 86-90.
2 Hulskamp G, Lum S, Stocks J, et al. Association of prematurity, lung disease and body size with lung volume and ventilation inhomogeneity in unsedated neonates: a multicentre study. Thorax 2009; 64: 240-245.

3 Latzin P, Roth S, Thamrin C, et al. Lung volume, breathing pattern and ventilation inhomogeneity in preterm and term infants. PLOS ONE 2009; 4: e4635.

4 Schulzke SM, Hall GL, Nathan EA, et al. Lung volume and ventilation inhomogeneity in preterm infants at 15-18 months corrected age. J Pediatr 2010; 156: 542-549.

5 Aurora P, Bush A, Gustafsson P, et al. Multiple-breath washout as a marker of lung disease in preschool children with cystic fibrosis. Am J Respir Crit Care Med 2005; 171: 249-256.

6 Aurora P, Gustafsson P, Bush A, et al. Multiple breath inert gas washout as a measure of ventilation distribution in children with cystic fibrosis. Thorax 2004; 59: 1068-1073.

7 Hoo AF, Thia LP, Nguyen TT, et al. Lung function is abnormal in 3-month-old infants with cystic fibrosis diagnosed by newborn screening. Thorax 2012; 67: 874-881.

8 Horsley AR, Macleod KA, Robson AG, et al. Effects of cystic fibrosis lung disease on gas mixing indices derived from alveolar slope analysis. Respir Physiol Neurobiol 2008; 162: 197-203.

9 Singer F, Stern G, Thamrin C, et al. A new double-tracer gas singlebreath washout to assess early cystic fibrosis lung disease. Eur Respir J 2013; 40: 339-345.

10 Downie SR, Salome CM, Verbanck S, et al. Ventilation heterogeneity is a major determinant of airway hyperresponsiveness in asthma, independent of airway inflammation. Thorax 2007; 62: 684-689.

11 Macleod KA, Horsley AR, Bell NJ, et al. Ventilation heterogeneity in children with well controlled asthma with normal spirometry indicates residual airways disease. Thorax 2009; 64: 33-37.

12 Verbanck S, Schuermans D, Vincken W. Inflammation and airway function in the lung periphery of patients with stable asthma. J Allergy Clin Immunol 2010; 125: 611-616.

13 Huygen PE, Gultuna I, Ince C, et al. A new ventilation inhomogeneity index from multiple breath indicator gas washout tests in mechanically ventilated patients. Crit Care Med 1993; 21: 1149-1158.

14 Verbanck S, Schuermans D, Meysman M, et al. Noninvasive assessment of airway alterations in smokers: the small airways revisited. Am J Respir Crit Care Med 2004; 170: 414-419.

15 Verbanck S, Schuermans D, Van Muylem A, et al. Conductive and acinar lung-zone contributions to ventilation inhomogeneity in COPD. Am J Respir Crit Care Med 1998; 157: 1573-1577.

16 Gustafsson PM, Aurora P, Lindblad A. Evaluation of ventilation maldistribution as an early indicator of lung disease in children with cystic fibrosis. Eur Respir J 2003; 22: 972-979.

17 Robinson PD, Latzin P, Verbanck S, et al. Consensus statement for inert gas washout measurement using multiple- and single-breath tests. Eur Respir J 2013; 41: 507-522.

18 Amin R, Subbarao P, Jabar A, et al. Hypertonic saline improves the LCI in paediatric patients with CF with normal lung function. Thorax 2010; 65: 379-383.

19 Amin R, Subbarao P, Lou W, et al. The effect of dornase alfa on ventilation inhomogeneity in patients with cystic fibrosis. Eur Respir J 2011; 37: 806-812.

20 Farah CS, King GG, Brown NJ, et al. Ventilation heterogeneity predicts asthma control in adults following inhaled corticosteroid dose titration. J Allergy Clin Immunol 2012; 130: 61-68.

21 Verbanck S, Schuermans D, Paiva M, et al. Small airway function improvement after smoking cessation in smokers without airway obstruction. Am J Respir Crit Care Med 2006; 174: 853-857.

22 Hall GL, Logie KM, Parsons F, et al. Air trapping on chest CT is associated with worse ventilation distribution in infants with cystic fibrosis diagnosed following newborn screening. PLOS ONE 2011; 6: e23932.

23 Singer F, Houltz B, Latzin P, et al. A realistic validation study of a new nitrogen multiple-breath washout system. PLoS ONE 2012; 7: e36083. 
24 Robinson PD, Latzin P, Gustafsson P. Multiple-breath washout. Eur Respir Monogr 2010; 47: 87-104.

25 Singer F, Stern G, Thamrin C, et al. Tidal volume single breath washout of two tracer gases - a practical and promising lung function test. PLOS ONE 2011; 6: e17588.

26 Yammine S, Singer F, Abbas C, et al. Multiple-breath washout measurements can be significantly shortened in children. Thorax 2012 [in press DOI: 10.1136/thoraxjnl-2012-202345].

27 Robinson PD, Stocks J, Aurora P, et al. Abbreviated multi-breath washout for calculation of lung clearance index. Pediatr Pulmonol 2012 [in press: DOI: 10.1002/ppul.22618].
28 Singer F, Kieninger E, Abbas C, et al. Practicability of nitrogen multiple-breath washout measurements in a pediatric cystic fibrosis outpatient setting. Pediatr Pulmonol 2012 [in press DOI: 10.1002/ppul.22651].

29 Parks YA, Beardsmore CS, MacFadyen UM, et al. The effect of a single breath of $100 \%$ oxygen on breathing in infants at 1, 2, and 3 months of age. Am Rev Respir Dis 1991; 144: 141-145.

30 Poets CF, Rau GA, Gappa M, et al. Comparison of heliox and oxygen as washing gases for the nitrogen washout technique in preterm infants. Pediatr Res 1996; 39: 1099-1102. 